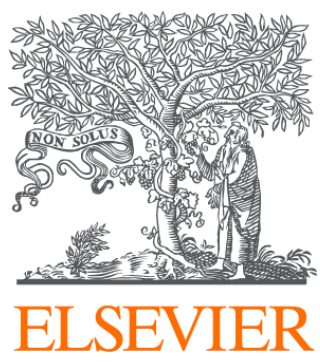

Since January 2020 Elsevier has created a COVID-19 resource centre with free information in English and Mandarin on the novel coronavirus COVID-

19. The COVID-19 resource centre is hosted on Elsevier Connect, the company's public news and information website.

Elsevier hereby grants permission to make all its COVID-19-related research that is available on the COVID-19 resource centre - including this research content - immediately available in PubMed Central and other publicly funded repositories, such as the WHO COVID database with rights for unrestricted research re-use and analyses in any form or by any means with acknowledgement of the original source. These permissions are granted for free by Elsevier for as long as the COVID-19 resource centre remains active. 


\section{When health professionals look death in the eye: the mental health of professionals who deal daily with the 2019 coronavirus outbreak}

\section{A R T I C L E I N F O}

\section{Keywords:}

Health professionals

COVID-19

Psychic exhaustion

\begin{abstract}
A B S T R A C T
Background: : The fact that COVID-19 is transmissible from human to human and associated with high morbidity and potentially fatality can intensify the perception of personal danger. In addition, the foreseeable shortage of supplies and an increasing flow of suspected and real cases of COVID-19 contribute to the pressures and concerns of health professionals.

Method: : The studies were identified in well-known international journals found in two electronic databases: Scopus and Embase. The data were cross-checked with information from the main international newspapers.

Results: : Work-related stress is a potential cause of concern for health professionals. It has been associated with anxiety including multiple clinical activities, depression in the face of the coexistence of countless deaths, long work shifts with the most diverse unknowns and demands in the treatment with patients with COVID-19. Therefore, it is an important indicator of psychic exhaustion.

Conclusions: : As coronavirus cases increase and deaths surge in Italy, new figures show an "enormous" level of contagion among the country's medical personnel. At least 2,629 health workers have been infected with coronavirus since the outbreak onset in February, representing $8.3 \%$ of total cases. The percentage of infected health workers has almost doubled the number registered in China throughout the epidemic. Intensive care unit physicians are on their stress limit, especially when dealing with older patients and with death prospects. Doctors, not a relative, are inevitably the last people a dying COVID-19 patient will see.
\end{abstract}

The novel coronavirus (COVID-19) outbreak continues to evolve, with more cases and quarantines popping up on news feeds everywhere. The closer it gets to their homes, the more people become worried. But what about people on the front lines? Nurses, doctors, healthcare workers, and other medical professionals who are testing for and treating patients with COVID-19 are at a higher risk of contracting it than the general public. What can they do to take care of themselves, physically and emotionally? (Magellan Health Insights, 2020). As if exposure to the COVID-19 during the global pandemic was not enough, healthcare workers face another risk: burnout due to overstress in an increasingly burdened healthcare system. The combination of stress and possible exposure puts healthcare professionals, from physicians and nurses to specialists, at greater risk of contracting COVID-19 and potentially spreading it to others (Health Care Finance, 2020).

Given this critical situation, health professionals directly involved in the diagnosis, treatment, and care of patients with COVID-19 develop the insertion of psychic spaces for the installation of pain and psychological suffering and other mental health symptoms. The growing number of confirmed and suspected cases, overwhelming workload, depletion of personal protective equipment, extensive media coverage, lack of specific medications and inadequate support feelings can contribute to the mental burden of these health professionals (State Council of China, 2020, Lai et al., 2020, Lee et al., 2007).

Work-related stress is a potential cause of concern for health professionals. It has been associated with anxiety including multiple clinical activities, depression in the face of the coexistence of countless deaths, long work shifts with the most diverse unknowns and demands in the treatment with patients with COVID-19. Therefore, it is an important indicator of psychic exhaustion (Adams and Walls, 2020;
Kushal et al., 2018). It is the classic rock-and-a-hard-place scenario healthcare workers and caregivers are desperately needed during the global response to the outbreak, but they represent one of the most vulnerable populations in terms of contracting the highly virulent disease (Admas and Walls, 2020).

The difficulty in assessing the extent to which health professionals have been affected emotionally is difficult because the Centers for Disease Control and Prevention (CDC), medical associations or unions of health professionals have not released worldwide data yet (Washington Post, 2020). Dozens of health care professionals on the front lines of the coronavirus pandemic have become ill with the coronavirus and more have been in quarantine after being exposed to it (Changing America, 2020).

The fact that COVID-19 is transmissible from human to human (Li et al., 2020, Rothe et al., 2020) and associated with high morbidity and potentially fatality can intensify the perception of personal danger (Wang, Tang and Wie, 2020). In addition, the foreseeable shortage of supplies and increasing flow of suspected and real cases of COVID-19 contribute to the pressures and concerns of health professionals (Lai et al., 2020, Adams and Walls, 2020, Kushal et al., 2018, ChanYeung, 2004). Coronavirus generates a lot of uncertainty, and this has resonance with health professionals who suffer or have suffered from anxiety and obsessive-compulsive disorder (OCD) in the treatment of patients in hospitals. Panic attacks can also be a response to the stress load linked to the coronavirus outbreak demands (The Guardian, 2020, Lai et al., 2020, Adams and Walls, 2020, Lee et al., 2007).

As coronavirus cases increase and deaths surge in Italy, new figures show an "enormous" level of contagion among the country's medical personnel. At least 2,629 health workers have been infected with 
coronavirus since the outbreak onset in February, representing $8.3 \%$ of total cases. The percentage of infected health workers has almost doubled the number registered in China throughout the epidemic (Aljazeera, 2020). Intensive care unit physicians are on their stress limit, especially when dealing with older patients and with death prospects. Doctors, not a relative, are inevitably the last people a dying COVID-19 patient will see (Lima et al., 2020, Carvalho et al., 2020, Moreira et al., 2020, Reteurs, 2020).

Despite the common mental health problems and disorders found among health professionals in such settings, most of those working in isolation units and hospitals are not trained to provide mental health care. Evidence highlights some timely mental health care that needs to be developed urgently, such as: use of psychotropic drugs, prescribed by psychiatrists for severe psychiatric comorbidities; specialized psychiatric treatments and appropriate mental health services and facilities for patients with comorbid mental disorders; psychic treatment plans, psychiatric illness progress reports, and health status updates for professionals in the Intensive Care Unit; regular updates to address their sense of uncertainty and fear; psychological counseling using electronic devices and applications (such as smartphones and WeChat); provision of emotional and behavioral responses to extraordinary stress, and psychotherapy techniques such as those based on the stress adaptation model (Xiang et al., 2020, Maunder et al., 2003, Folkman and Greer, 2000).

\section{Authors' contributions}

MLRN, MMM, CKTL, CGLS, JGJ and NNRL designed the review, developed the inclusion criteria, screened titles and abstracts, appraised the quality of included papers, and drafted the manuscript.

HGA, JDE, CBN, CRTO and WRP reviewed the study protocol and inclusion criteria and provided substantial input to the manuscript.

MLRN, NNRL, ICS and OMMLL reviewed the study protocol. MMM read and screened articles for inclusion. All authors critically reviewed drafts and approved the final manuscript.

\section{Funding}

The Suicidology Research Group from Universidade Federal do Ceará (UFC) and Brazilian National Council for Scientific and Technological Development (CNPq) - institution linked to the Brazilian Department of Science, Technology and Innovation to encourage research in Brazil.

\section{Declaration of competing interest}

The authors declare that they have no competing interests.

\section{Acknowledgements}

The authors would like to thank the Suicidology Research Group from Universidade Federal do Ceará (UFC) and the Brazilian National Council for Scientific and Technological Development (CNPq) - institution linked to the Brazilian Department of Science, Technology and
Scientific Writing Lab, Medicine School - Universidade Federal of Cariri (UFCA).

\section{References}

Magellan Health Insights, 2020. Addressing anxiety about the coronavirus (COVID-19): Healthcare workers. https://magellanhealthinsights.com/2020/03/12/addressinganxiety-about-the-coronavirus-covid-19-healthcare-workers/.

Health Care Finance, 2020. Healthcare workers risk burnout, exposure in wake of coronavirus pandemic. https://www.healthcarefinancenews.com/news/healthcareworkers-risk-burnout-exposure-wake-coronavirus-pandemic.

The State Council of China, 2020. A notification to set up nationwide psychological assistance hotlines against the 2019-nCoV outbreak. http://www.gov.cn/xinwen/ 2020-02/02/content_5473937.htm.

Lai, J., Ma, S., Ma, Wang, Y., Cai, Z., Hu, J., Wei, N., Wu, J., Du, H., Chen, T., Li, R., Tan, H., Kang, L., Yao, L., Huang, M., Wang, H., Wang, G., Liu, Z., Hu, S., 2020. Factors associated with mental health outcomes among health care workers exposed to coronavirus disease. JAMA Network Open 3, e203976.

Lee, A.M., Wong, J.G., McAlonan, G.M., et al., 2007. . Stress and psychological distress among SARS survivors 1 year after the outbreak. Can J Psychiatry 52, 233-240.

Adams, J.G., Walls, R.M., 2020. Supporting the Health Care Workforce During the COVID-19 Global Epidemic. JAMA. https://doi.org/10.1001/jama.2020.3972.

Kushal, A., Gupta, S., Metha, M., Singh, M.M., 2018. Study of Stress among Health Care Professionals: A Systemic Review. Int J Res Foundation Hosp Healthcare Adm 6, 6-11.

Washington Post, 2020. Covid-19 hits doctors, nurses and EMTs, threatening health system. https://www.washingtonpost.com/health/covid-19-hits-doctors-nursesemts-threatening-health-system/2020/03/17/f21147e8-67aa-11ea-b313df458622c2cc_story.html.

Changing America, 2020. US health care workers furloughed, quarantined due to coronavirus exposure. https://thehill.com/changing-america/well-being/preventioncures/488059-us-health-care-workers-furloughed-quarantined.

Li, Q., Guan, X., Wu, P., et al., 2020. . Early transmission dynamics in Wuhan, China, of novel coronavirus-infected pneumonia. N Engl J Med.

Rothe, C., Schunk, M., Sothmann, P., et al., 2020. . Transmission of 2019-nCoV infection from an asymptomatic contact in Germany. N Engl J Med. https://doi.org/10.1056/ NEJMc2001468.

Wang, W., Tang, J., Wei, F., 2020. Updated understanding of the outbreak of 2019 novel coronavirus (2019-nCoV) in Wuhan, China. J Med Virol 92, 441-447.

Chan-Yeung, M., 2004. Severe acute respiratory syndrome (SARS) and healthcare workers. Int J Occup Environ Health 10, 421-427.

Guardian, The, 2020. Anxiety on rise due to coronavirus, say mental health charities. Anxiety on rise due to coronavirus, say mental health charities. https://www. theguardian.com/world/2020/mar/13/anxiety-on-rise-due-to-coronavirus-saymental-health-charities.

Aljazeera, 2020. Thousands of medical staff infected with coronavirus in Italy. https:// www.aljazeera.com/news/2020/03/rising-number-medical-staff-infectedcoronavirus-italy-200318183939314.html.

Reuters, 2020. Special Report: 'All is well'. In Italy, triage and lies for virus patients. https://www.reuters.com/article/us-health-coronavirus-italy-ethics-speci/specialreport-all-is-well-in-italy-triage-and-lies-for-virus-patients-idUSKBN2133KG.

Lima, C.K.T., Carvalho, P.M.M., Lima, I.A., Nunes, J.V.A.O., Saraiva, J.S., Souza, R.I., Silva, C.G.L., Rolim Neto, M.L., 2020. The emotional impact of Coronavirus 2019. nCoV (new Coronavirus disease). Psychiatry Research 287, 112915.

Carvalho, P.M.M., Moreira, M.M., Oliveira, M.N.A., Landim, J.M.M., Rolim Neto, M.L., 2020. The psychiatric impact of the novel coronavirus outbreak. Psychiatry Research $286,112902$.

Moreira, M.M., Rolim Neto, M.L., 2020. What does the future hold for doctors and suicide? Psychiatry Research 285, 112832.

Xiang, Y.T., Yang, Y., Li, W., Zhang, L., Zhang, Q., Cheung, T., Chee, H.N.G., 2020. Timely mental health care for the 2019 novel coronavirus outbreak is urgently needed. The Lancet 7, 228-229.

Maunder, R., Hunter, J., Vincent, L., et al., 2003. . The immediate psychological and occupational impact of the 2003 SARS outbreak in a teaching hospital. CMAJ 168, $1245-1251$.

Folkman, S., Greer, S., 2000. Promoting psychological well-being in the face of serious illness: when theory, research and practice inform each other. Psychooncology 9, 11-19. 
Modesto Leite Rolim Neto ${ }^{\mathrm{a}, \mathrm{d}, *}$, Hiure Gomes Almeida ${ }^{\mathrm{a}}$, Joana D'arc Esmeraldo ${ }^{\text {, Camila Bezerra Nobre }}{ }^{\text {a }}$, Woneska Rodrigues Pinheiro ${ }^{\mathrm{b}}$, Cícera Rejane Tavares de Oliveira ${ }^{\mathrm{b}}$, Itamara da Costa Sousa ${ }^{b}$, Onélia Maria Moreira Leite Lima ${ }^{c}$,

Nádia Nara Rolim Lima ${ }^{\mathrm{e}}$, Marcial Moreno Moreira, ${ }^{\mathrm{a}, \mathrm{c}, \mathrm{c}}$, Carlos Kennedy Tavares Lima ${ }^{c}$, Jucier Gonçalves Júnior ${ }^{f}$, Claúdio Gleideston Lima da Silva ${ }^{\text {a,d }}$

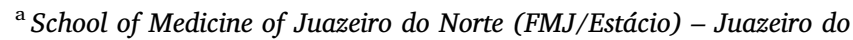
Norte, Ceará, Brazil

${ }^{\mathrm{b}}$ Regional University of Cariri - URCA, Crato, Ceará, Brazil
${ }^{\mathrm{c}}$ Postgraduate Program in Health Sciences, School of Medicine of ABC, Santo André, São Paulo, Brazil

${ }^{\mathrm{d}}$ School of Medicine, Federal University of Cariri (UFCA) - Barbalha, Ceará, Brazil

e Suicidology Research Group, Universidade Federal do Ceará (UFC) Fortaleza, Ceará, Brazil

${ }^{\mathrm{f}}$ Department of Internal Medicine, Santa casa de Misericórdia de Fortaleza, Fortaleza, Ceará, Brazil E-mail address: modesto.neto@ufca.edu.br (M.L.R. Neto). 